University of Arkansas, Fayetteville

ScholarWorks@UARK

Graduate Theses and Dissertations

$5-2012$

\title{
A Behavioral Test of Contamination Fear in Excessive Health Anxiety
}

Robert Edwin Brady

University of Arkansas, Fayetteville

Follow this and additional works at: https://scholarworks.uark.edu/etd

Part of the Applied Behavior Analysis Commons, and the Health Psychology Commons

\section{Citation}

Brady, R. E. (2012). A Behavioral Test of Contamination Fear in Excessive Health Anxiety. Graduate Theses and Dissertations Retrieved from https://scholarworks.uark.edu/etd/318

This Dissertation is brought to you for free and open access by ScholarWorks@UARK. It has been accepted for inclusion in Graduate Theses and Dissertations by an authorized administrator of ScholarWorks@UARK. For more information, please contact scholar@uark.edu. 

A BEHAVIORAL TEST OF CONTAMINATION FEAR IN EXCESSIVE HEALTH ANXIETY 


\section{A BEHAVIORAL TEST OF CONTAMINATION FEAR IN EXCESSIVE HEALTH}

\section{ANXIETY}

A dissertation submitted in partial fulfillment

of the requirements for the degree of

Doctor of Philosophy in Psychology

By

Robert E. Brady

University of Georgia

Bachelor of Arts in Psychology, 2004

University of Arkansas

Master of Arts in Clinical Psychology, 2009

May 2012

University of Arkansas 


\begin{abstract}
Hypochondriasis and health anxiety are characterized by preoccupation with the fear of currently having a serious physical illness. The Diagnostic and Statistical Manual of Mental Disorders conceptualization of hypochondriasis does not include consideration of the fear of acquiring an illness; however, many individuals with severe health anxiety report concern about contamination, suggesting that the current conceptualization of hypochondriasis may be incomplete. The present study utilized behavior approach tasks (BATs) to examine the degree to which contamination fear is present in severe health anxiety. Additionally, perceived vulnerability to disease (PVD) and disgust were tested as potential mechanisms in health anxiety and contamination fear. Results showed that health anxious individuals were similarly avoidant of sources of contamination, and reported similar anxiety and disgust in response to the BATs. Regression analyses showed that PVD, but not disgust, potentiated the effect of both health anxiety and contamination fear in the prediction of disgust experienced during the BATs. The theoretical and clinical implications of these findings are discussed.
\end{abstract}


This dissertation is approved for recommendation to the Graduate Council.

Dissertation Director:

Dr. Jeffrey Lohr

Dissertation Committee:

Dr. Matthew Feldner

Dr. William Levine 


\section{DISSERTATION DUPLICATION RELEASE}

I hereby authorize the University of Arkansas Libraries to duplicate this dissertation when needed for research and/or scholarship.

Agreed

Robert E. Brady

Refused

Robert E. Brady 


\section{ACKNOWLEDGEMENTS}

I owe special thanks to Dr. Jeff Lohr for his mentorship and guidance throughout my graduate training. He is a model of excellence in the field of psychology. His knowledge, professionalism, intellectual curiosity, and commitment to a science of psychology are unparalleled, and I am fortunate to be his student.

I would like to thank my colleague, Tom Adams, for his friendship and collaborative spirit during the course of our training. I am greatly appreciative of his help during the course of this dissertation, and I wish him the best in his continued training as the sole member of the Lohr Lab. I also thank Ashlyn Testut, Andrew Arnett, and Kara Foster for their help in data collection on this study.

Finally, I thank my friends and family for their love and support during my graduate training. 


\section{DEDICATION}

This dissertation is dedicated to my grandmother, Penny Brady. 


\section{TABLE OF CONTENTS}

I. Introduction 1

II. Method 9

$\begin{array}{lll}\text { III. } & \text { Results } & 16\end{array}$

$\begin{array}{ll}\text { IV. Discussion } & 24\end{array}$

V. References 33

$\begin{array}{lll}\text { VI. } & \text { Table and Figures } & 38\end{array}$ 


\section{INTRODUCTION}

The Diagnostic and Statistical Manual of Mental Disorders ( $4^{\text {th }}$ Edition, Text revision; DSM-IV-TR; American Psychiatric Association [APA], 2000) describes the essential feature of hypochondriasis (HC) as a "preoccupation with fears of having, or the idea that one has a serious disease" and lists it among the somatoform disorders due to the preoccupation with bodily symptoms. This preoccupation occurs in the absence of a diagnosed physical condition, or is made when the fear is disproportional to the severity of a diagnosed physical illness. The disorder is considered to be a result of the misinterpretation of physical symptoms that occurs in the absence of an etiological basis that can be determined by medical evaluation. This may take the form of catastrophic misinterpretation of painful, but benign, symptoms (e.g., assuming stomach cancer in the presence of diarrhea), or misinterpretation of vague physical sensations (e.g., assuming the presence of a brain tumor due to "head pressure").

\section{History of the disorder}

The historical origins of $\mathrm{HC}$ are unique among the somatoform disorders in that recognition of the behavior patterns exhibited by individuals presenting with $\mathrm{HC}$ has been formally documented since the $16^{\text {th }}$ century (Berrios, 2001). The Greeks have been cited as the earliest theorists of the disorder, at which time it may have been considered a disorder of the bodily organs positioned just below (hypo-) the chondria (i.e., the cartilage lining the breastbone). Later writers described $\mathrm{HC}$ as a disorder of melancholy arising from humoral disturbances. This suggests an early basis in physical causes of the disorder which, in turn, may have contributed to the use of this term to describe the fear of physical dysfunction characterizing current models of HC. 
The modern psychiatric classification of $\mathrm{HC}$ is also noteworthy, as it was originally classified among the neuroses in the DSM-II (APA, 1968), along with anxiety neurosis, phobia neurosis, depressive neurosis, and others. The DSM-II description is similar to the current diagnostic depiction in that it is "dominated by preoccupation with the body and with fear of presumed diseases of various organs" (p. 41). The increased emphasis on diagnostic reliability and categorization in the DSM-III (APA, 1980) resulted in creation of the somatoform disorders category in which $\mathrm{HC}$ was placed. However, the loose association of the somatoform disorders based on their body-focused nature, at the expense of considering their functional dissimilarities, has led some to call for the removal of HC from the somatoform disorders, and alternative classification as an anxiety disorder (Noyes, 1999).

\section{Current models of hypochondriasis}

Early attempts to determine the factors underlying $\mathrm{HC}$ resulted in a model consisting of disease conviction and disease phobia (Bianchi, 1973; Kellner, 1986; Pilowsky, 1967). Subsequent statistical and theoretical analyses have provided support for the differentiation of these two constructs (Cote et al., 1996; Fergus \& Valentiner, 2010; Salkovskis, Warwick, \& Clark, 1990). The former term refers to the individual's often strongly held belief that they presently have a disease. That is, the preoccupation that characterizes HC is one in which the individual comes to believe that they have an undiagnosed illness in the present moment. This is distinguished from a preoccupation that they will have a disease at some point in the future. Taylor and Asmundson (2004) posit that disease conviction is most typical of the traditional view of HC.

Disease phobia refers to the fear of currently having an illness. This includes a fear of the consequences of having an illness, or more generally as a fear of simply being physically ill. 
This includes catastrophic thoughts about the personal costs of having an illness, the potential negative effect that having an illness might have on longevity, and the belief that the illness will result in death. For example, an individual presenting with disease phobia specific to HC may fear the repercussions that having cancer has on the ability to live a normal life, as well as the fact that the illness is likely to result in a long and especially painful death. The overlap in terminology between disease phobia, as it relates to $\mathrm{HC}$, and specific phobia of illness presents a potential source of confusion within the literature. Part of the confusion in language may be attributable to the variability in the types of illnesses capturing the concern of health anxious individuals. An individual diagnosed with HC may fear either a systemic illness such as cancer, or a contagious illness such as meningitis. Importantly, the emphasis in the DSM criteria is on the fear that the individual already has the illness, rather than the fear that they may acquire the illness later.

Contemporary theoretical models of HC have generally furthered the concept of disease phobia and disease conviction as distinct factors in HC (Barsky, 1992; Taylor \& Asmundson, 2004; Warwick \& Salkovskis, 1990). The presence of these factors predicts the patterns of behavior observed in clinical presentations of $\mathrm{HC}$, suggesting that these factors improve conceptualization of the disorder. For example, an individual high in disease conviction would demonstrate excessive checking behavior and more somatic complaints. An individual presenting with $\mathrm{HC}$ dominated by disease phobia would describe having an illness as especially unbearable, and would likely exhibit distress when presented with illness cues and avoidance of such reminders. A presentation of $\mathrm{HC}$ in which both factors are present would correspondingly show increased checking behavior motivated by both the intense fear of having an illness (disease phobia), and resistance to reassurance motivated by the certainty of illness (disease 
conviction). HC remains a poorly understood and under-researched disorder despite the attempts to better delineate its underlying factors (Abramowitz, 2008; Noyes, 2005). Noyes (2001) has highlighted the need for research focused on further identifying the distinguishing features that differentiate $\mathrm{HC}$ from other disorders, as a means of clarifying the diagnostic boundaries of the disorder. The present study attempts to clarify the role of contamination fear in HC, as a means of elucidating mechanisms that differentiate $\mathrm{HC}$ from other forms of health-focused psychopathology.

\section{Disease phobia vs. fear of contagion and contamination}

The DSM conceptualization of HC does not include the fear of contracting an illness as a prerequisite for diagnosis of the disorder. This form of illness fear is typically subsumed under the diagnosis of specific phobia of illness, in which the focus of the fear is coming into contact with potential sources of illness. For example, the fear of contracting human immunodeficiency virus (HIV) may be expressed by a belief that walking by an individual with HIV might result in accidental contraction of the virus. This results in avoidance of stimuli, including other people, and environments that may make transmission of an illness more likely. Noyes, Carney, and Langbehn (2004) recently reviewed the criteria for specific phobia of illness with an emphasis on the contrasting features that distinguish illness phobia from HC. They note concern over immediate threats to health, fear of specific illnesses, and the absence of somatic concerns as distinguishing features of specific phobia of illness. They conclude that illness phobia and HC are best considered distinct and discernable disorders.

The fear of contracting an illness is also commonly observed among individuals diagnosed with obsessive-compulsive disorder (OCD) of which the principle concern is the possibility of contracting a contaminant. This fear is met with attempts to either prevent contact 
with the source of contamination, or if contact cannot be prevented, to neutralize the threat posed by the contaminant. This disorder often takes the form of simple (e.g., not using public restrooms) or elaborate avoidance strategies (e.g., wearing protective gloves and masks while using public transportation), and ritualized cleansing behaviors (e.g., washing a predetermined number of times after touching a potential source of contamination). The focus on health and wellness among individuals presenting with symptoms of contamination-based OCD may lead to diagnostic boundaries regarding the degree to which $\mathrm{HC}$ and OCD are related.

These examples underscore a potential source of disagreement regarding the optimal conceptualization of HC: whether the presence of a fear of contracting an illness through contamination and contagion should be considered a core feature of the disorder (Marks, 1987; Taylor \& Asmundson, 2004). As previously discussed, the DSM-IV-TR criteria do not include mention of fears of contracting illness as an element of HC. However, several authors have suggested that the fear of contracting an illness is an important component of the disorder (Marks, 1987; Taylor \& Asmundson, 2004). Part of the conflation of disease phobia with the fear of contracting an illness may lie in the use of the term phobia. The term "phobia" denotes a pervasive fear response composed of a pattern of behavioral, cognitive, and physiological manifestations (Lang, 1970; Rachman, 1978) resulting from close proximity to a dreaded object or situation. A specific phobia of illness, or simply "illness phobia," refers to the "fear of ... contracting an illness" (APA, 2000) and leads to "avoidance of situations that may lead to contracting an illness" (APA, 2000). It follows that an individual with illness phobia would likely avoid coming into contact with stimuli that would increase the perceived probability of becoming ill through the spread of some form of contagion. The differential diagnosis provided by the DSM-IV-TR clearly states that distinguishing between $\mathrm{HC}$ and illness phobia can be 
achieved by noting the presence or absence of the belief that one presently has an illness. The DSM-IV-TR goes on to add that individuals with HC are "preoccupied with fears of having a disease, whereas individuals with a specific phobia fear contracting a disease (but do not believe it is already present)" (italics added). Thus, the authors of the DSM-IV-TR appear to support a model of $\mathrm{HC}$ that is not based on the presence of a fear of contracting an illness, though they do not rule it out as a potential concomitant.

The DSM-IV-TR is less precise about the distinction between HC and contaminationbased OCD. The differential diagnosis for $\mathrm{HC}$ and OCD states that a diagnosis of $\mathrm{HC}$ should be made when cognitive symptoms are restricted to the fear of having a disease, unless the fear is accompanied by compulsive behaviors such as excessive washing or checking to prevent contracting or spreading illness. A diagnosis of OCD is suggested when these additional symptoms are observed, or when the fear of having a disease co-occurs with other, non-illnessrelated obsessive thoughts (APA, 2000). Thus, the differential diagnosis of HC and OCD relies on the presence of multiple obsessive thoughts focused on a variety of stimuli or situations, or the presence of compulsive behaviors performed to reduce the chance of contamination and subsequent disease. This description again implies the presence of contamination fear in OCD, and the absence of contamination fear in HC. However, no studies have experimentally tested the degree to which contamination fear is present or absent in $\mathrm{HC}$ relative to contaminationbased OCD. To the contrary, an emerging body of literature suggests that contamination-based OCD and HC share elevated levels of disgust (Deacon \& Olatunji, 2007; Olatunji, 2009) as a common process that may be prominent in the development of contamination fears. Hypochondriasis as a disorder of health anxiety 
The active debate regarding disease phobia and the fear of contracting an illness as distinguishable forms of psychopathology has led to an increased focus on the function of anxiety in HC. The increased interest on fear and anxiety as the dominant emotional responses in $\mathrm{HC}$ has resulted in the development of the term health anxiety (HA). The use of this term has surreptitiously entered the current literature on $\mathrm{HC}$ to the point that $\mathrm{HA}$ and $\mathrm{HC}$ are often used synonymously. The primary difference between these terms hinges on the consideration of HC as a categorical construct with discrete boundaries; however, as previously discussed these boundaries remain undetermined (Noyes, 2001). The use of HA connotes a dimensional category of psychopathology with HC falling along one end of the dimension. Research showing that individuals with HC exhibit intense fear and anxiety in response to perceived threats to health has supported the view that HC is best considered a form of HA (Warwick, 1989; Taylor \& Asmundson, 2004). Indeed, several authors have referred to HC as a form of extreme HA (Abramowitz, Schwartz, \& Whiteside, 2002; Warwick \& Salkovskis, 1990). Thus, it is useful to consider HA as the form of psychopathology underlying $\mathrm{HC}$, and subsequently for HC to be a diagnostic category representing severe HA. This is especially useful given the recognized limitations of the conceptual boundaries of $\mathrm{HC}$ as a formal diagnosis. Disgust and disease avoidance in contamination fear and health anxiety

Disgust is a basic emotional response that may have evolved as a means of preventing the oral incorporation of noxious substances (e.g., illness-inducing substances) (Rozin \& Fallon, 1987; Rozin, Haidt, \& McCauley, 2000). Several authors have pointed to the function of disgust as a "disease-avoidance mechanism" (Matchett \& Davey, 1991; Oaten, Stevenson, \& Case, 2009; Tybur, Lieberman, \& Griskevicius, 2009) which motivates behaviors that reduce the possibility of illness via contamination. The disease-avoidance effect of disgust results in 
behavioral avoidance of potential sources of contamination. This effect can be observed in a variety of clinical phenomena. Clinical research on the relation between disgust as a diseaseavoidance mechanism has primarily focused on the development and maintenance of contamination fear within the context of OCD (David et al., 2009; Olatunji et al., 2010; Tolin, Woods, \& Abramowitz, 2006; Tsao \& McKay, 2004). These studies generally show an effect of elevated trait disgust as a predictor of contamination-based OCD.

Recent research has also implicated disgust in HA and HC. Olatunji (2009) demonstrated specificity of disgust in HA such that disgust predicted HA even after controlling for contamination fears. Similarly, Thorpe, Patel, and Simonds (2003) reported a significant relation between HA and disgust. This study also found that HA was the greatest predictor of washing compulsions relative to disgust and general worry. The results of this study in particular argue for a relation between disgust, washing compulsions (in response to contamination fear), and HA in which disgust best predicted washing frequency, and HA best predicted washing distress. Finally, Davey and Bond (2006) reported findings in support of disgust sensitivity, defined as the appraisal of the threat signaled by the disgust response, but not trait disgust in the prediction of HA. These studies provide initial support for the role of disgust in HA. A subsequent study conducted by Duncan, Schaller, and Park (2009) provides a connection between research on the relation between disgust and contamination concerns, and disgust and HA. The authors propose that a general perception of oneself as susceptible to illness underlies contamination fear, and that this perception is related to the maladaptive disgust response that characterizes contamination fear. Furthermore, the authors demonstrated that perceived vulnerability to disease may also contribute to the development of HA.

\section{Present study}


The present study had two primary aims. The first aim was to use a behavioral test to determine the degree to which contamination fear is present in HA, as an analogue of HC. The DSM-IV-TR criteria suggest that fear of contamination and subsequent contagion is not a core feature of $\mathrm{HC}$; however, this assumption has not been tested in an experimental format. The available evidence gleaned from descriptive, correlational studies suggests that the current HC criteria may underestimate the presence of contamination fear in hypochondriacal individuals. This study tested the role of contamination fear in HA using a behavioral approach task (BAT). The BAT methodology has been used substantially in the study of various forms of psychopathology, especially anxiety (Deacon \& Olatunji, 2007; Olatunji, Lohr, Sawchuk, \& Tolin, 2007; Koch, O’Neill, Sawchuk, \& Connolly, 2002; Steketee, Chambless, Tran, Worden, \& Gillis, 1996). The procedure followed in the present study provides a behavioral test of contamination fear in HA by comparing avoidance of sources of contamination by individuals reporting elevated HA typical of individuals meeting criteria for $\mathrm{HC}$ to that of individuals reporting elevated contamination fear typical of individuals meeting criteria for contaminationbased OCD, and a non-anxious comparison group. The second aim of the present study was to test the relation between psychopathology, disgust, and perceived vulnerability to disease in the prediction of avoidance and anxiety in response to sources of contamination. A presentation of the specific study hypotheses is presented in the Method section following a review of the measurement instruments and study procedures.

\section{METHOD}

\section{Participants}

Sixty participants were recruited from the general psychology research pool at a large southern university $(62 \%$ female, $M$ age $=20.2)$. Participants were selected on the basis of 
scores on the Short Health Anxiety Inventory (SHAI; Salkovskis, Rimes, Warwick, \& Clark, 2002) and contamination-washing subscale of the Padua Inventory-Revision (PI-COWC; Burns, Keortge, Formea, \& Sternberger, 1996). Students voluntarily completed the SHAI and contamination subscale of the PI-COWC as part of a screening procedure conducted at the start of each semester in which the study was conducted. A cut-off score of 14 on the PI-COWC was used to approximate the clinical analogue of contamination-based OCD and is based on the findings of Burns et al. (1996), which suggested this score as an appropriate clinical cut-off. A cut-off of 25 on the SHAI was used to approximate the non-clinical analogue of HC. This score fell two standard deviations below the mean for the clinical sample from Salkovskis et al. (2002), and two standard deviations above the means of the student samples from Salkvoskis et al. and Abramowitz, Olatunji, and Deacon (2007). This score was also two standard deviations above the mean from the overall sample of respondents from the undergraduate research pool. These scores were used to form the three participant groups for the present study. Participants assigned to the health anxious group had scores greater than 25 on the SHAI, and less than 16 on the PICOWC. Conversely, participants assigned to the contamination-fearful group had scores greater than 16 on the PI-COWC, and less than 25 on the SHAI. Finally, participants in the non-anxious control (NAC) group had scores of less than 14 and 25 on the PI-COWC and SHAI, respectively. Participants were offered course credit in exchange for participation in the present study.

\section{Self-report Measures}

The Short Health Anxiety Inventory (SHAI; Salkovskis et al., 2002) is a brief version of the Health Anxiety Inventory (Salkovskis et al., 2002). The SHAI includes 18 items assessing an individual's level of HA. Factor analyses have generally supported a three factor solution for the SHAI (Abramowitz, Deacon, \& Valentiner, 2007; Abramowitz, Olatunji, \& Deacon, 2007). The 
three factors include Illness Likelihood (IL), Illness Severity (IS), and Body Vigilance (BV). The SHAI possesses excellent psychometric properties, with Cronbach's alphas ranging from .86 to .96 (Abramowitz, Deacon et al., 2007; Abramowitz, Olatunji et al., 2007; Salkovskis et al., 2002).

The contamination and washing subscale of the Padua Inventory-Washington State University Revision (PI-COWC; Burns, Keortge, Formea, \& Sternberger, 1996) is comprised of 10 items assessing attitudes toward potential sources of contamination and related behavior (e.g., washing). Endorsement of items is rated along a five-point Likert-type scale from not at all to very much. The PI-COWC has been shown to possess good convergent validity with other measures of contamination fear in the context of assessment of OCD symptoms (Jonsdottir \& Smari, 2000). Burns et al. (1996) reported high internal consistency (Cronbach's $\alpha=.85$ ) and good test-retest reliability $(r=.72)$ for the contamination subscale, as well as an overall internal consistency of .92 .

The Perceived Vulnerability to Disease questionnaire (PVD; Duncan, Schaller, \& Park, 2009) is a 15-item measure designed to assess an individual's beliefs about their risk of infection from sources of contamination and illness. Respondents rate their endorsement of each item along a seven-point Likert scale $(0=$ strongly disagree, $7=$ strongly agree $)$. The PVD is comprised of two factors, perceived infectability and germ aversion, each posited to affect an individual's perception of vulnerability to illness. The PVD is a recently published measure and psychometric data are scarce; however, initial tests of the PVD suggest adequate reliability (Cronbach's $\alpha=.82$ ). Duncan et al. also reported a modest correlation between the two factors $(r=.30)$ which provides some support for the utility of the two factors for differential prediction 
of perceived vulnerability to disease. However, the total score was chosen in the present study to assess susceptibility to illness as a single construct.

The Disgust Propensity and Sensitivity Scale-Revised (DPSS-R; van Overveld et al., 2002) is a 16-item measure used to assess trait disgust (i.e., DP) and perceptions of the consequence of feeling disgusted (i.e., DS). The DPSS-R possesses adequate reliability using internal consistency as an index of reliability (Cronbach's $\alpha$ 's $>.71$ ). Factor analyses have confirmed the original two-factor solution of the DPSS-R consisting of the propensity and sensitivity factors (Olatunji, Cisler, Deacon, Connolly, \& Lohr, 2007; van Overveld et al., 2006). Additionally, van Overveld et al. reported high correlations between the propensity subscale and the Disgust Scale (DS; Haidt et al., 1994), a measure of trait disgust.

The Neuroticism subscale of the brief version of the Eysenck Personality QuestionnaireRevised (EPQ-NR; Eysenck, Eysenck, \& Barrett, 1985) is a 12-item measure assessing an individual's predisposition to experiencing negative affect. Ratings are dichotomized into 'yes' or 'no' responses to determine whether an item (e.g., "Would you call yourself tense or 'highlystrung?") is an accurate reflection of the respondent. The EPQ-NR has demonstrated good internal consistency (Cronbach's $\alpha=0.82$ ). Test-retest reliability for the EPQ-NR is not available.

The State-Trait Anxiety Inventory (STAI; Spielberger, Gorsuch, Lushene, Vagg, \& Jacobs, 1983) was used to assess state and trait levels of anxiety. The STAI consists of two separate forms, one assessing state anxiety and the other assessing trait anxiety. Each form consists of 20 items measured on a 4-point Likert scale (1 = "Almost never", 4 = "Almost always"). The manual for the STAI reports median test-retest reliability coefficients for the state and trait forms of 0.33 and 0.70 , respectively. The low test-retest reliability for the state form is 
expectable given the nature of the scale as a measure of situational anxiety. Internal consistency was high for both scales. Median Cronbach's alphas for the state and trait forms are 0.93 and 0.90 .

\section{Behavioral Approach Tasks}

Four behavioral approach tasks (BATs) were administered during the study. Three of these BATs were adapted from prior studies of contamination fear (Deacon \& Olatunji, 2007; Deacon \& Maack, 2008). Each BAT consisted of three steps, with each step resulting in greater exposure to potential contamination. The number of steps completed was recorded by the experimenter for each BAT. The first BAT consisted of asking the participant to hold a used comb in one hand, run the used comb through his or her hair, and touching the used comb to his or her lips. In the second BAT, the participant was presented with a cookie placed on the floor of the experimental area. The participant was asked to pick up the cookie, touch the cookie to his or her lips, and eat the cookie. The third BAT consisted of asking the participant to touch the upper surface of a bedpan filled with toilet water while wearing a rubber glove, submerging his or her protected hand into the toilet water, and removing the glove and re-submerging his or her hand in the toilet water. A fourth BAT was designed specifically for the proposed study. This BAT also consists of three steps, to maintain consistency with the previously validated BATs. The participant was presented with a button-down dress shirt which was purported to have been donated by a patient of the Washington County HIV and AIDS clinic. The shirt was placed ten feet from the participant. The steps of this BAT included the participant approaching the shirt, picking up and holding the shirt, and putting on the shirt over his or her clothing. The order of BAT administration was fully randomized. The participant was informed that the BAT procedures were "not tests of courage," and that they were "free to refuse to do all or any part of 
the tasks or to do them only partially." The inclusion of this instruction is consistent with the prior research and was intended to minimize risk of emotional distress to the participant, as well as limiting the possibility of demand characteristics. A participant's decision not to participate in a BAT resulted in a zero step score for that BAT, and inversely, a maximum avoidance score of three for that BAT. The participant was informed of the nature of each step for all BATs before they decided whether to proceed. Additionally, participants were asked to provide a verbal rating of anxiety and disgust separately on a $0-10$ scale $(0=$ no anxiety, $10=$ extreme anxiety $)$ after each completed step of each BAT.

Internal Consistency of the Study BATs

Internal consistency of the BATs used in the present study, including the BAT created specifically for this study (i.e., the HIV shirt), was adequate (Cronbach's $\alpha=0.82$ ).

Additionally, moderate to strong correlations were found between the HIV shirt BAT and the other BATs on avoidance (range in $r^{\prime} \mathrm{s}=0.38-0.62$, all $p$ 's $<0.005$ ), anxiety (range in $r$ 's $=$ 0.47-0.63, all p's < 0.005), and disgust (range in $r$ 's $=0.35-0.69$, all $p$ 's < 0.05).

\section{Procedure}

Participants were invited to attend a single experimental session based on the screening and selection criteria described above. Participants were provided with a standard informed consent process upon arrival to the laboratory. Participants were then administered the four BATs. They then completed a series of self-report measures including the DPSS-R, PVD, SHAI, EPQ-N, and the PI-COWC. Participants were then debriefed at the conclusion of the procedure. Debriefing information included acknowledgement that the bedpan was filled with clean tap water, and that the shirt was a newly purchased men's shirt not previously owned by an AIDS patient. Participants were advised to report to the Psychological Clinic in the event that they 
experienced excessive HA or contamination fear and were provided with referral information to the Psychological Clinic. Participants selected from the student population were assigned course credit for their participation and dismissed.

\section{Hypotheses}

BAT Results. There are three dependent variables in the proposed study that inform the degree to which contamination fear is a relevant process in HA: 1) avoidance, measured by the number of steps refused in each BAT, 2) anxiety, measured by the mean self-reported anxiety in each BAT, and 3) disgust, measured by the mean self-reported disgust in each BAT.

Hypothesis 1: There will be a main effect of group on the number of BAT steps refused.

Hypothesis 1a: The health anxiety (HA) and contamination fear (CF) groups will refuse a greater number of BAT steps compared to the non-anxious comparison group.

Hypothesis 1b: The HA and CF groups will not differ in the number of BAT steps refused.

Hypothesis 2: There will be a main effect of group on the self-reported anxiety ratings.

Hypothesis 2a: The HA and CF groups will report greater anxiety in response to the BAT steps compared to the non-anxious comparison group.

Hypothesis 2b: The HA group will report greater anxiety in response to the BAT steps compared to the CF group.

Hypothesis 3: There will be a main effect of group on the self-reported disgust ratings.

Hypothesis 3a: The HA and CF groups will report greater disgust in response to the BAT steps compared to the non-anxious comparison group.

Hypothesis 3b: The CF group will report greater disgust in response to the BAT steps compared to the HA group. 
Regression Tests. A series of regressions were conducted to test the interactions of group membership and perceived vulnerability to disease (PVD), and group membership and trait disgust, on avoidance, anxiety, and disgust. The regressions statistically controlled for gender, neuroticism, and trait anxiety.

Hypothesis 4: There will be significant main effects of group and PVD in the prediction of avoidance, as well as a group X PVD interaction predicting avoidance beyond that of the main effects of group and PVD.

Hypothesis 5: There will be significant main effects of group and PVD in the prediction of anxiety in response to the BATs, as well as a group X PVD interaction predicting anxiety beyond that of the main effects of group and PVD.

Hypothesis 6: There will be significant main effects of group and PVD in the prediction of disgust in response to the BATs, as well as a group X PVD interaction predicting disgust beyond that of the main effects of group and PVD.

Hypothesis 7: There will be significant main effects of group and trait disgust in the prediction of avoidance, as well as a group $\mathrm{X}$ trait disgust interaction predicting avoidance beyond that of the main effects of group and trait disgust.

Hypothesis 8: There will be significant main effects of group and trait disgust in the prediction of anxiety, as well as a group $\mathrm{X}$ trait disgust interaction predicting anxiety beyond that of the main effects of group and trait disgust.

Hypothesis 9: There will be significant main effects of group and trait disgust in the prediction of disgust, as well as a group $\mathrm{X}$ trait disgust interaction predicting disgust beyond that of the main effects of group and trait disgust.

\section{RESULTS}




\section{Participant Characteristics}

BAT variable and other study measure means and standard deviations are presented for the individual group samples in Table 1. Groups did not differ on age, $F(2,56)=2.21, p=0.12$, but they did differ on gender, $\chi^{2}(2, N=60)=14.20, p<0.001$. This was due to greater frequency of males in the NAC group. Gender was included as a covariate in all subsequent analyses.

\section{Zero-order Correlations between BAT variables and Study Measures}

Zero-order correlations between the indices for avoidance, anxiety, and disgust, and the total scores for the study measures are presented in Table 2. A Bonferroni-correction was applied to these data ( 0.05 divided by 21 correlations) resulting in a stringent alpha level of 0.002. All correlations reached this level (all $p$ 's $<0.002)$ with the exception of the SHAI $(p=$ 0.01), which failed to meet the Bonferroni-corrected alpha level for the correlation with avoidance; however, it was significantly correlated with the remaining study variables, suggesting that no variable was uniquely related to the outcome measures.

\section{Post-selection Validation of Group Membership}

Multiple pairwise comparisons were performed to ensure appropriate group membership (HA vs. CF vs. NAC) after pre-study selection of participants. This analysis was performed using the participants SHAI and PI-COWC total scores from the measures completed during the study. Six comparisons were made requiring a Bonferroni-correction to control for Type I error rate (0.05 divided by the six comparisons) resulting a stringent alpha level of 0.008 . All group differences were significant at the 0.008 level, indicating appropriate group membership based on the two measures.

Effect of Psychopathology on BAT Avoidance 
The result of a one-way ANCOVA suggested a highly significant difference among groups on avoidance during the BATs, $F(2,53)=6.49, p<.005$, after controlling for the effects of gender, neuroticism (EPQ-N), and trait anxiety (STAI-T). Three planned comparisons were performed to test the relation between the groups on avoidance. A Bonferroni correction was applied to these comparisons to account for multiple comparisons. Results of these comparisons showed that avoidance exhibited by the HA $(M=6.7,95 \%$ CI $[5.31,8.09])$ and CF $(M=6.91$, $95 \%$ CI $[5.76,8.06])$ groups was significantly greater than that of the NAC group $(M=3.34$, 95\% CI [1.85, 4.83]), but not significantly different from each other (Figure 1.). The observed power for the effect of group in this analysis was 0.89 . Effect of Psychopathology on BAT Anxiety

An initial one-way ANCOVA was conducted to test the effect of group on anxiety experienced during the BATs; however, a violation of the assumption of homogeneity of variances was observed for this analysis. A review of normality diagnostics and the graphical distribution of data between groups suggested that strong positive skewness of the anxiety ratings for the NAC group likely contributed to heterogeneity of variances. A logarithmic transformation of the mean anxiety ratings was conducted, consistent with the recommendation of Tabachnick and Fidell (2007). A subsequent one-way ANCOVA showed a significant effect of group on anxiety, $F(2,53)=8.21, p<.005$. Three planned comparisons were also conducted to test the group differences on anxiety. A Bonferroni correction was also applied to this analysis. These results demonstrated that anxiety reported by the CF group (untransformed $M=$ $3.04,95 \% \mathrm{CI}[2.27,3.81])$ was significantly greater than that of the NAC group (untransformed $M=0.55,95 \% \mathrm{CI}[0.17,0.93])$, but not significantly greater than that of the HA group 
(untransformed $M=2.67,95 \%$ CI $[1.83,3.5]$ ) (Figure 2). The observed power for the effect of group in this analysis was 0.95 .

Effect of Psychopathology on BAT Disgust

Finally, a third one-way ANCOVA was performed to test the effect of group on disgust experienced during the BATs. A similar concern regarding normality of the distribution, and subsequently, for homogeneity of variances, was raised for the disgust ratings, prompting a logarithmic transformation. A subsequent ANCOVA revealed a significant effect of group on disgust ratings, $F(2,53)=9.55, p<.001$. Three planned comparisons were again conducted to test the group differences on disgust. These comparisons showed an effect on disgust similar to that of anxiety such that the CF group (untransformed $M=3.84,95 \%$ CI $[2.98,4.71]$ ) was significantly greater than that of the NAC group (untransformed $M=0.95,95 \%$ CI $[0.52,1.38]$ ), but not significantly greater than that of the HA group (untransformed $M=3.38,95 \%$ CI [2.56, 4.21]) (Figure 3). The observed power for the effect of group in this analysis was 0.98 . Potentiating Effect of Perceived Vulnerability to Disease in Health Anxiety

A second set of analyses was conducted to test the potentiating effect of PVD on the prediction of avoidance, anxiety, and disgust reported during the BATs. Multiple regression analyses were first utilized to test the main effect of group on avoidance during the BATs, followed by the interaction of group and PVD. Importantly, three separate regression equations were constructed for this analysis because the predictor variable of interest, group, was comprised of three levels. The decision to conduct the analysis in this manner was made on the basis of the recommendations of Aiken and West (1991) in their guidelines for interpreting interactions involving three or more groups, as well as for ease of interpretation. The authors suggest that dummy variables be used for each comparison, noting that $G-1$ dummy variable 
will be needed, where $G$ is the number of groups. This resulted in the creation of two dummy variables, $O$ and 1 . The dummy variables were coded for the analyses such that the NAC group was always assigned the dummy code of 0 , making it the comparison, and the pathological group was always assigned the dummy code of 1 , making it the criterion for each analysis. The CF group was assigned the dummy code of 0 when $\mathrm{CF}$ and HA were the only two levels in the analysis. This was done arbitrarily and did not affect the interpretation of the slopes of the predictors. Group (HA and NAC, CF and NAC, or CF and HA), PVD, and the Group X PVD interaction term were then simultaneously entered into the three regression equations for avoidance. Each equation also included gender, neuroticism, and trait anxiety as covariates. All predictor variables were first centered using the sample means for each predictor prior to including them in the equation. All significant interaction effects were subsequently subjected to post-hoc probing to better illustrate the effect of the predictor of interest (i.e., group) across different levels of either PVD or DPSS-R.

The first set of regressions tested the combined effects of group and PVD on the dependent variables. The first equation from this set was formed by regressing avoidance scores on the three covariates (i.e., gender, neuroticism, and trait anxiety), PVD, group (HA and NAC), and the interaction between group and PVD. There was a significant main effect of group $(\mathrm{B}=$ $1.42, t=2.05, p=.05)$. This showed that health anxious individuals were significantly more avoidant than the non-anxious controls. There was no significant main effect for PVD and the interaction term was also non-significant. The second regression assessed the combined effect of PVD and group on anxiety. Mean anxiety for the four BATs, with a logarithm transformation to correct for moderate positive skew, was regressed on the three covariates, PVD, group, and the interaction term. There was a significant main effect of group $(\mathrm{B}=.14, t=2.22, p=.03)$, but no 
significant main effect of PVD or the interaction. The third analysis assessed the combined effect of PVD and group on disgust, and revealed a significant main effect of group $(\mathrm{B}=.14, t=$ 2.34, $p=.03)$ and a marginally significant interaction of group and $\mathrm{PVD}(\mathrm{B}=.01, t=1.98, p=$ .06). This interaction is displayed in Figure 4. It is necessary to note that the scores depicted in Figure 4 are logarithm-transformed scores for mean anxiety, and thus show only the relation between the group differences, rather than actual mean scores. The interaction demonstrates that group membership (i.e., presence or absence of HA) is a stronger predictor of disgust when PVD is elevated (i.e., $+1 S D)(\mathrm{B}=.5, t=3.96, p<.001)$ relative to when $\mathrm{PVD}$ is low (i.e., $-1 S D)(\mathrm{B}=$ $.18, t=1.63, p=.11)$.

\section{Potentiating Effect of Disgust in Health Anxiety}

A second set of regressions was conducted to test the combined effect of group and disgust, as measured by the DPSS-R, on the study variables for the HA and NAC samples. The first regression again showed a significant effect of group $(\mathrm{B}=1.83, t=2.37, p=.02)$ on avoidance, but no significant main effect of DPSS-R or the interaction. The second regression also showed a significant main effect of group $(\mathrm{B}=.14, t=2.14, p=.04)$ on anxiety, but no main effect of DPSS-R or the interaction. A nearly identical result was found for the third regression for which there was a main effect of group $(\mathrm{B}=.14, t=2.18, p=.04)$ for disgust, but no significant effects of DPSS-R or the interaction.

\section{Potentiating Effect of Perceived Vulnerability to Disease in Contamination Fear}

These six regressions were then replicated for the CF and NAC groups with similar results. The first analysis regressed avoidance on the covariates, PVD, group (CF and NAC), and the interaction of group and PVD. This analysis revealed a significant main effect of group ( $\mathrm{B}=2.9, t=2.4, p=.02)$, but no significant effects of PVD or the interaction. The second 
analysis also showed a significant effect of group $(\mathrm{B}=.28, t=2.86, p=.007)$ on anxiety, but no significant effects for PVD or the interaction. The third analysis showed a significant main effect of group $(\mathrm{B}=.3, t=3.02, p=.005)$ on disgust in the BATs, as well as a significant interaction of PVD and group $(\mathrm{B}=.01, t=2.22, p=.03)$. The main effect of PVD was nonsignificant. The interaction is presented in Figure 5. This interaction shows that group membership (i.e., presence or absence of CF) is a stronger predictor of disgust when PVD is elevated $(\mathrm{B}=.56, \mathrm{t}=5.47, \mathrm{p}<.001)$, than when PVD is low $(\mathrm{B}=.26, t=1.72, p=.09)$. This effect is nearly identical to the group by PVD effect observed among the HA group.

\section{Potentiating Effect of Disgust in Contamination Fear}

The last three analyses examined the combined effect of DPSS-R and group restricted to the $\mathrm{CF}$ and NAC groups. These results mirrored that of the HA and NAC groups such that there was a significant effect of group in the prediction of avoidance $(\mathrm{B}=3.03, t=2.55, p=.02)$, anxiety $(\mathrm{B}=.28, t=3.00, p=.005)$, and disgust $(\mathrm{B}=.29, t=3.05, p=.005)$, but no main effects of DPSS-R or the interaction.

\section{Supplemental Analyses Using Continuous Predictor of Health Anxiety}

A supplementary set of analyses was also performed in recognition of the limitations of a smaller sample size in the previous analyses involving a categorical variable composed of three levels and split into two separate sets of analyses. The supplemental analyses tested the effects of HA and contamination fear as continuous variables (i.e., assessed by the SHAI and PI-COWC, respectively), as well as the interactions between these variables and PVD and DPSS-R scores. The first analysis tested the effects of SHAI and PVD, as well as the interaction of these scores in the prediction of avoidance on the BATs. This analysis showed a significant main effect of PVD $(\mathrm{B}=.07, t=3.48, p=.001)$, a marginally significant main effect of SHAI $(\mathrm{B}=.08, t=$ 
$1.84, p=.07)$, and a significant interaction of SHAI and PVD (B -.003, $t=-2.1, p=.04)$. This interaction is presented in Figure 6. The post-hoc probing of this significant interaction showed that SHAI score is a stronger predictor of avoidance on the BATs when PVD is low $(\mathrm{B}=.1, t=$ $2.15, p=.04)$ compared to when PVD is high $(\mathrm{B}=-.03, t=-.91, p=.37)$. Tests of the effects of SHAI, PVD, and their interaction on the anxiety and disgust ratings revealed no significant main effects or interactions for the variables of interest.

Regressions were also conducted to test the interactive effect of SHAI and DPSS-R in the prediction of the dependent variables. Avoidance was regressed on SHAI, DPSS-R, and the interaction. No significant main effects or interaction were observed. This was also true of the analysis of the SHAI and DPSS-R effects on anxiety for which no significant main effects or interaction was observed. Not surprisingly, a significant main effect of DPSS-R was found when SHAI and DPSS-R were regressed on the disgust ratings; however, the important interaction term was non-significant $(p=.32)$.

Supplemental Analyses Using Continuous Predictor of Contamination Fear

An identical set of analyses was conducted to explore the role of PI-COWC as a continuous predictor of avoidance, anxiety, and disgust on the BATs, as well as the interactions between PI-COWC and PVD, and PI-COWC and DPSS-R. The regression of avoidance on PICOWC and PVD showed a significant main effect of PI-COWC $(\mathrm{B}=.09, t=2.03, p=.05)$. The main effect of PVD and the interaction were both non-significant. This effect was also seen for anxiety and disgust ratings, in which there was a main effect of PI-COWC on anxiety $(\mathrm{B}=.01, t$ $=3.05, p=.004)$ and disgust $(\mathrm{B}=.01, t=3.88, p<.001)$, but no additional significant effects.

Finally, multiple regressions were conducted to test the effects of PI-COWC, DPSS-R, and their interaction on the outcome variables. These analyses showed a consistent pattern in 
which PI-COWC, but not DPSS-R, predicted avoidance $(\mathrm{B}=.17, t=3.38, p=.001)$, anxiety ratings $(\mathrm{B}=.01, t=2.94, p=.005)$, and disgust ratings $(\mathrm{B}=.01, t=3.31, p=.002)$ on the BATs. The interaction terms were also non-significant for the avoidance $(p=.17)$, anxiety ratings $(p=$ $.89)$, and disgust ratings $(p=.77)$.

\section{DISCUSSION}

\section{Summary of Results}

The present study had two primary aims that further the understanding of health anxiety (HA), and by extension, the diagnosis of hypochondriasis (HC). The first aim was to clarify the relative effects of HA and contamination fear on avoidance of contamination threat, as well as anxiety and disgust experienced in the presence of contamination threat. This was achieved by subjecting individuals reporting elevated HA, contamination fear, or neither form of psychopathology (non-anxious controls; NAC) to a series of behavioral approach tasks (BATs). The primary outcome variable for the BATs was the number of steps completed by the participants on each BAT, resulting in the creation of an index of avoidance. Avoidance was then compared across groups, the result of which failed to demonstrate differences between the health anxious and contamination fearful participants. Both pathological groups were significantly more avoidant during the BATs compared to the NAC group. This finding was consistent with the study hypothesis that HA and contamination fearful individuals would not exhibit differences in avoidance behavior in the presence of sources of contamination. The absence of a difference in avoidance suggests that individuals with elevated HA are at least as avoidant as individuals with pronounced contamination fear, for whom the fear of illness by contamination is a source of motivation for avoidance (Rachman, 2004). This relation was found after controlling for the effects of gender, neuroticism, and trait anxiety. Moreover, these results 
were robust, even among a convenience sample comprised of individuals not diagnosed with HC or contamination-based OCD. This result provides support for the conceptualization of HA as a form of psychopathology partially characterized by a fear of acquiring illness via incidental contact with contaminants.

A different pattern of findings was observed when evaluating the emotional concomitants of behavioral avoidance. The results of the analyses of subjective anxiety and disgust experienced during the BATs only partially supported the study hypotheses. As predicted, individuals with elevated contamination fear were significantly more likely to experience disgust after completing the BAT steps, relative to the NAC group. This hypothesis was based on consistent findings in the literature demonstrating that contamination fear is partly a function of an individual's tendency toward, and aversion for, experiencing disgust (Rozin \& Fallon, 1987; Tolin, Woods, \& Abramowitz, 2006). Conversely, the literature in support of disgust as an emotional mechanism in HA is limited, and is based largely on correlational data (Olatunji, 2009; Thorpe, Patel, \& Simonds, 2003). The present finding is consistent with this literature, such that elevated contamination fear, but not HA, was associated with a more intense disgust response in the presence of contamination threat relative to individuals reporting neither form of psychopathology.

The finding that the contamination fear (CF) group, but not the HA group, was significantly different from the NAC group on anxiety ratings during the BATs was surprising, and contrary to the study hypothesis. It was predicted that the HA group would report more anxiety in response to the BATs relative to the NAC group; however, this effect failed to emerge. The hypothesis was based on the assumption that HA, as the term implies, is primarily a problem of fear and anxiety, as well as several studies showing a tendency for elevated anxiety and 
intolerance of this emotional response (Abramowitz, Deacon, \& Valentiner, 2007; Cox, Borger, \& Enns, 1999). There are at least two potential explanations for the absence of the anticipated effect. First, the violations of normality and homogeneity of variances for the anxiety and disgust ratings may have weakened the ability to detect a significant difference for the HA group; however, this is unlikely given the observed differences for the CF group. Additionally, the transformation of these data obviated this concern. A second and more plausible explanation is that HA may be more prevalent among individuals with a general neurotic quality that leads the individual to be more avoidant of threat in general (Noyes et al., 2005). The utilization of statistical controls to reduce the effects of third variables such as neuroticism, and emphasize the effect of contamination fear, may have artificially suppressed phenomenological variables that are central to the emotional response of these individuals. Miller and Chapman (2001) raised this issue in their critique of the inclusion of covariates in ANCOVA that may actually account for a critical part of the independent variable. They argue that attempting to exclude the potential effect of a covariate on a dependent variable when the covariate is statistically related to the independent variable changes the independent variable in a meaningful way. This results in modification of the independent variable such that it no longer measures what it was intended to measure and obfuscates the actual effect of the independent variable on the dependent variable. For example, an individual with elevated neuroticism may be more likely to rate a potential source of contamination as especially anxiety provoking, even though they may be less concerned about the actual contaminating properties. Thus, inclusion of covariates that account for variance attributed to a construct such as neuroticism may limit the effect of a construct that is a crucial determinant of an individual's emotional response (i.e., neuroticism). While this certainly improves the understanding of how contamination fear functions in HA, it may 
ultimately prevent understanding of HA itself. Indeed, a post-hoc analysis of the means for the EPQ-N and STAI-T showed that the HA group differed significantly from the CF and NAC groups on these measures. However, Zinbarg, Suzuki, Uliaszek, and Lewis (2010) provide a counter-argument to the admonitions of Miller and Chapman, stating that the selection and use of covariates in ANCOVA is acceptable when the question addressed by the study design is whether a specific component of the independent variable is related to the dependent variable. This would apply to the present study. The focus of the study is whether contamination fear among the three groups differentially affected behavior on the BATs, independent of neuroticism, trait anxiety, and gender. The specification of contamination fear as the residual effect of interest, after partialing the effects of neuroticism, trait anxiety, and gender from group, is consistent with Zinbarg et al. (2010) as an appropriate use of covariate selection in ANCOVA.

The second aim of the study was to determine the potentiating effects of perceived vulnerability to disease (PVD), a cognitive construct, and disgust, an emotional construct, on HA. The presence of a significant interaction of PVD and group (when group was dichotomized to include only HA and NAC participants) on disgust ratings showed that individuals with excessive HA report more disgust when they have a greater sense that they are more susceptible to disease. This effect was also found for the $\mathrm{CF}$ group when only $\mathrm{CF}$ and NAC participants were included in the analysis. This result can be understood when considering the proposed function of disgust as an evolutionarily-based mechanism to reduce the likelihood of illness through incorporation of a contaminant (Oaten et al., 2009). That is, an individual with a belief that they are more likely to contract a disease may experience a stronger disgust response when faced with contamination threat as a motivation for increased distance between their self and the contaminant source. This may even mean preparing for gustatory rejection of the offending 
substance in the evolutionary sense of the disgust response (Rozin \& Fallon, 1986). The present study suggests that individuals with psychopathology combined with a greater sense of vulnerability to disease are more likely to respond with disgust in the presence of contamination threat.

The absence of significant interactions between group and PVD in the prediction of avoidance and anxiety is surprising given the theoretical assumption that greater perceived susceptibility to disease and infection would function to increase the effect of psychopathology on these variables. This may have been due to a generally low level of actual risk associated with the BATs, such that the groups were not differentially predictive of avoidance and anxiety scores at different levels of PVD. This initially seems contrary to the explanation for the significant effects seen for disgust. However, it is likely that most individuals perceived the tasks as disgusting, and that those who had an increased sense of disease susceptibility viewed the tasks as more disgusting. This may have been due to increased threat value perceived in the tasks as a result of their perceived vulnerability to infection from them. Participants providing higher ratings of anxiety and refusing to approach would be more likely in cases where actual threat was anticipated. A manipulation check to ascertain the believability of the tasks as true sources of contamination would be needed to rule out this explanation.

The supplementary analyses of SHAI and PI-COWC scores as predictors of the dependent measures provides additional information that may clarify the relation between HA and contamination fear. These analyses were conducted on a post-hoc basis due to concerns that the relatively small sample size across the three levels of the categorical variable may have limited the ability to determine significant interaction and main effects. The interaction between SHAI scores and PVD in the prediction of avoidance was the only significant interaction effect 
to emerge from the full array of analyses, though significant main effects of PI-COWC scores were present in each analysis in which it was included as a predictor. The post-hoc probing of the significant interaction showed that SHAI scores were only predictive of avoidance at low levels of PVD. This effect provides some support for PVD as an important construct in HA. The lack of a significant effect of HA at high levels of PVD suggests that an individual's tendency to experience anxiety about their health is only predictive of avoidance of contamination when their perception of their self as susceptible to illness is low. That is, when PVD is elevated, HA no longer appears to be a relevant determinant of avoidance. This implies a higher-order function of PVD in the behavioral manifestations of HA.

Lastly, the lack of any significant interactions between disgust and group in the initial analyses, and disgust and the continuous predictors in the supplementary analyses was also contrary to expectations. The consistent finding that disgust functions as an affective motivator for avoidance of contamination among contamination fearful individuals (Tolin, Woods, \& Abramowitz, 2006), as well as health anxious individuals to a lesser degree (Olatunji, 2009), invited the hypothesis that this would potentiate the effect of HA and contamination fear on the study variables. The absence of the predicted effect is difficult to explain and may simply be a consequence of selecting the DPSS-R as the index of disgust. It is possible that the consideration of the DPSS-R as a nuanced measure of disgust comprised of two factors (i.e., propensity and sensitivity) may have obscured the relation between disgust and the measures of psychopathology. The choice of a measure considered a better index of trait disgust (e.g., the Disgust Scale) may provide a clearer understanding of the role of disgust in the potentiation of HA and contamination fear.

Implications for Clinical Care 
The potential for improving conceptualization and clinical procedures in the treatment of HA was a primary motivation for the present study. One important question addressed in the present study was whether consideration of fear of illness acquisition would be appropriate for a health-anxious population. Standard cognitive-behavioral conceptualization and clinical procedures exist for treatment of $\mathrm{HC}$ and have been demonstrated effective for the population of interest. However, these current models and procedures do not directly address the fear of illness acquisition, especially through means of contagion. The failure to account for illness acquisition fears would likely hamper attempts to decrease problematic HA among the hypochondriacal population, leading to inadequate treatment and suboptimal outcomes. For example, a typical treatment approach for $\mathrm{HC}$ involves imaginal exposure to having a feared illness (e.g., imagining that one has received a diagnosis of chronic obstructive pulmonary disease), exposure to illnessrelated cues (e.g., visiting a respiratory therapy clinic), and resisting the urge to seek additional tests (e.g., resisting the urge to schedule a chest X-ray). Exposure to the possibility of acquiring an illness through contamination (e.g., exposure to the possibility of contact with an undetected fume by visiting a coal-burning power plant) would likely not be included in a typical treatment for HC. The observation that individuals with elevated HA were similarly averse to contamination threat compared to contamination-fearful individuals suggests a need to consider fear of illness acquisition in treatment of HA. Accordingly, treatment providers would be welladvised to consider including a treatment component aimed at decreasing fear and avoidance of contamination to attain the maximum treatment effect. This could be easily incorporated into the pre-existing treatment procedures, as it is consistent with cognitive-behavioral treatment, in general, and exposure-based treatment more specifically.

\section{Limitations}


The present study includes several limitations that restrict the conclusions that can be drawn from the data. First, the participants recruited for the study were drawn from a student population, and thus provide only an analogue test of $\mathrm{HC}$ and contamination-based OCD. Several recent studies support the use of analogue samples in the study of various forms of psychopathology, especially when the psychopathology is normally distributed in the general population (Borkovec \& Rachman, 1979; Cox, Enns, Borger, \& Parker, 1999). Thus, these results likely provide an adequate estimate of the way in which HA and contamination fear function in the general population, and by extension, in the clinical phenomena they approximate.

There was an initial attempt to recruit a clinical sample for inclusion in the HA and CF groups; however, an extremely low response rate (i.e., one non-student volunteer who did not satisfy screening requirements) precluded this aim. The feasibility of recruiting a clinical sample of hypochondriacal, or even abridged HC (i.e., clinically elevated HA without disease conviction or clinically impairing disease phobia) is poor given the low base rate of $\mathrm{HC}$, and resistance of health anxious individuals to recognizing their illness concerns as a psychological problem. A subsequent replication of this study is planned in a medical facility providing access to a primary care facility as part of a larger study of HA.

Finally, the absence of an anxious control group limits the clarity of the study conclusions. The use of a Neuroticism subscale of the EPQ, and subsequent statistical control of these data, were intended to remove the confound of general neuroticism from the study findings. Nonetheless, control of phenomenological confounds through an improved study design is a more preferable means of restricting or eliminating the variance explained by these variables than statistical control. Thus, a replication of the present study should include an anxious control 
group to remove the influence of neuroticism on avoidance in a contamination BAT. Socially anxious individuals would likely provide an acceptable anxious control group given the presumably limited role of social anxiety in avoidance of sources of contamination. This addition would allow for a clearer test of the effect of contamination fear in HA relative to contamination fear beyond the shared effect of neuroticism.

Despite these limitations, the present study informs the literature on HA by providing a behavioral assessment of contamination fear in a form of psychopathology that is often thought of as unrelated to this fear. The results showed that aversion toward contact with sources of contamination is similar among individuals with HA relative to contamination fear as a distinct form of psychopathology. Furthermore, these forms of psychopathology were clearly distinguishable on multiple variables with the exception of the degree to which individuals in either group responded with avoidance, anxiety, and disgust on the BATs. This supported the primary hypothesis that the health anxious and contamination-fearful groups would exhibit similar contamination fear on the BATs relative to a non-anxious control sample. Finally, analyses of constructs related to both forms of psychopathology showed that PVD is functionally related to HA and contamination fear. 


\section{REFERENCES}

Abramowitz, J. S. (2008). New directions in health anxiety: Introduction to the special issue. Journal of Cognitive Psychotherapy, 22, 83-86. doi:10.1891/0889-8391.22.2.83.

Abramowitz, J. S., Deacon, B. J., \& Valentiner, D. P. (2007). The short health anxiety inventory: Psychometric properties and construct validity in a non-clinical sample. Cognitive Therapy and Research, 31, 871-883. doi:10.1007/s10608-006-9058-1.

Abramowitz, J. S., Olatunji, B. O., \& Deacon, B. J. (2007). Health anxiety, hypochondriasis, and the anxiety disorders. Behavior Therapy, 38, 86-94. doi:10.1016/j.beth.2006.05.001.

Abramowitz, J. S., Schwartz, S. A., \& Whiteside, S. P. (2002). A contemporary conceptual model of hypochondriasis. Proceedings of the Mayo Clinic, 77, 1323-1330.

Aiken, L. S., \& West, S. G. (1991). Multiple regression: Testing and interpreting interactions. Newbury Park, CA: Sage.

American Psychiatric Association. (1968). Diagnostic and statistical manual of mental disorders $\left(2^{\text {nd }}\right.$ ed.). Washington, DC: Author.

American Psychiatric Association. (1980). Diagnostic and statistical manual of mental disorders $\left(3^{\text {rd }}\right.$ ed.). Washington, DC: Author.

American Psychiatric Association. (2000). Diagnostic and statistical manual of mental disorders ( $4^{\text {th }}$ ed., text rev.). Washington, DC: Author.

Asmundson, G. J. G., Taylor, S., \& Cox, B. J. (2001). Health anxiety: Clinical and research perspectives on hypochondriasis and related disorders. New York, NY: Wiley.

Barsky, A. J. (1992). Hypochondriasis and obsessive-compulsive disorder. Psychiatric Clinics in North America, 15, 791-801.

Berrios, G. E. (2001). Hypochondriasis: History of the concept. In V. Starcevic \& D. R. Lipsitt (Eds.) Hypochondriasis: Modern perspectives on an ancient malady (pp. 3-20). New York: Oxford University Press.

Bianchi, G. N. (1973). Patterns of hypochondriasis: A principal components analysis. British Journal of Psychiatry, 122, 541-548. doi:10.1192/bjp.122.5.541.

Burns, G. L., Keortge, S. G., Formea, G. M., \& Sternberger, L. G. (1996). Revision of the Padua inventory of obsessive compulsive disorder symptoms: distinctions between worry, obsessions, and compulsions. Behaviour Research and Therapy, 34, 163-173.

Cote, G., O'Leary, T., Barlow, D. H., Strain, J. J., Salkovskis, P. M., Warwick, H. M. C., ...Rasmussen, S. A. (1996). Hypochondriasis. In T. A. Widiger, A. J. Frances, H. A. 
Pincus, R. Ross, M. B. First, \& W. W. Davis (Eds.), DSM-IV sourcebook (Vol 2., pp. 933-947). Wasington, DC: American Psychiatric Association.

Cox, B. J., Borger, S. C., \& Enns, M. W. (1999). Anxiety sensitivity and emotional disorders: psychometric studies and their theoretical implications. In: S. Taylor (Ed.), Anxiety sensitivity: Theory, research, and treatment of the fear of anxiety (pp. 115-148). Mahwah, NJ: Lawrence Erlbaum.

Davey, G. C. L., \& Bond, N. (2006). Using controlled comparisons in disgust psychopathology research: The case of disgust, hypochondriasis, and health anxiety. Journal of Behavior Therapy and Experimental Psychiatry, 37, 4-15.

David, B., Olatunji, B. O., Armstrong, T., Ciesielski, B. G., Bondy, C. L., \& Broman-Fulks, J. (2009). Incremental specificity of disgust sensitivity in the prediction of obsessivecompulsive disorder symptoms: Cross-sectional and prospective approaches. Journal of Behavior Therapy and Experimental Psychiatry, 40, 1-11.

Deacon, B., \& Maack, D. J. (2008). The effects of safety behaviors on the fear of contamination: An experimental investigation. Behaviour Research and Therapy, 46, 537-547.

Deacon, B., \& Olatunji, B. O. (2007). Specificity of disgust sensitivity in the prediction of behavioral avoidance in contamination fear. Behaviour Research and Therapy, 45, 2110 2120 .

Duncan, L. A., Schaller, M., \& Park, J. H. (2009). Perceived vulnerability to disease: Development and validation of a 15-item self-report instrument. Personality and Individual Differences, 47, 541-546.

Eysenck, S. B. G., Eysenck, H. J., \& Barrett, P. (1985). A revised version of the psychoticism scale. Personality and Individual Differences, 6, 21-29.

Fergus, T. A., \& Valentiner, D. P. (2010). Disease phobia and disease conviction are separate dimensions underlying hypochondriasis. Journal of Behavior Therapy and Experimental Psychiatry, 41, 438-444. doi:10.1016/j.jbtep.2010.05.002.

Haidt, J., McCauley, C., \& Rozin, P. (1994). Individual differences in sensitivity to disgust: A scale sampling seven domains of disgust elicitors. Personality and Individual Differences, 16, 701-713.

Jonsdottir, S. D., \& Smari, J. (2000). Measuring obsessions without worry: convergent and discriminant validity of the revised Padua inventory in an Icelandic student population. Scandinavian Journal of Behaviour Therapy, 29, 49-56.

Kellner, R. (1986). Somatization and hypochondriasis. New York: Praeger. 
Koch, M. D., O’Neill, K., Sawchuk, C. N., \& Connolly, K. (2002). Domain-specific and generalized disgust sensitivity in blood-injection-injury phobia: The application of behavioral approach/avoidance tasks. Anxiety Disorders, 16, 511-527.

Lang, P. J. (1970). Stimulus control, response control, and the desensitization of fear. In D. J. Levis (Ed.) Learning approaches to therapeutic behavior change (pp. 148-173). Chicago: Aldine.

Marks, I. M. (1987). Fears, phobias, and rituals. New York, NY: Oxford Press.

Matchett, G., \& Davey, G. C. L. (1991). A test of a disease-avoidance model of animal phobias. Behaviour Research and Therapy, 29, 91-94. doi:10.1016/S0005-7967(09)80011-9.

Miller, G. A., \& Chapman, J. P. (2001). Misunderstanding analysis of covariance. Journal of Abnormal Psychology, 110, 40-48.

Noyes, R. (1999). Relationship of hypochondriasis to anxiety disorders. General Hospital Psychiatry, 21, 8-17.

Noyes, R. (2001). Hypochondriasis: Boundaries and comorbidities. In G. J. G. Asmundson, S. Taylor, \& B. J. Cox (Eds.) Health anxiety: Clinical and research perspectives on hypochondriasis and related disorders (pp. 132-160). New York, NY: Wiley.

Noyes, R. (2005). Hypochondriasis: A review. In M. Maj, H. S. Akiskal, J. E. Mezzich, \& A. Okasha (Eds.) Somatoform disorders (pp. 129-189). New York: John Wiley \& Sons.

Noyes, R., Carney, C. P., \& Langbehn, D. R. (2004). Specific phobia of illness: search for a new subtype. Journal of Anxiety Disorders, 18, 531-545.

Noyes, R., Watson, D. B., Letuchy, E. M., Longley, S. L., Black, D. W., Carney, C. P., \& Doebbeling, B. N. (2005). Relationship between hypochondriacal concerns and personality dimensions and traits in a military population. Journal of Nervous and Mental Disease, 193, 110-118.

Oaten, M., Stevenson, R. J., \& Case, T. I. (2009). Disgust as a disease-avoidance mechanism. Psychological Bulletin, 135, 303-321.

Olatunji, B. O. (2009). Incremental specificity of disgust propensity and sensitivity in the prediction of health anxiety dimensions. Journal of Behavior Therapy and Experimental Psychiatry, 40, 230-239.

Olatunji, B. O., Cisler, J. M., Deacon, B. J., Connolly, K. M., \& Lohr, J. M. (2007). The Disgust Propensity and Sensitivity Scale-Revised: Psychometric properties and specificity in relation to anxiety disorder symptoms. Journal of Anxiety Disorders, 21, 918-930. doi:10.1016/j.janxdis.2006.12.005. 
Olatunji, B. O., Cisler, J. M., McKay, D., \& Phillips, M. L. (2010). Is disgust associated with psychopathology? Emerging research in the anxiety disorders. Psychiatry Research, 175, $1-10$.

Olatunji, B. O., Lohr, J. M., Sawchuk, C. N., \& Tolin, D. F. (2007). Multimodal assessment of disgust in contamination-related obsessive-compulsive disorder. Behaviour Research and Therapy, 45, 263-276.

Pilowsky, I. (1967). Dimensions of hypochondriasis. British Journal of Psychiatry, 113, 39-43.

Rachman, S. (1978). Human fears: A three systems analysis. Scandinavian Journal of Behaviour Therapy, 7, 237-245.

Rozin, P., \& Fallon, A. E. (1987). A perspective on disgust. Psychological Review, 94, 23-41. doi:10.1037/0033-295X.94.1.23.

Rozin, P., Haidt, J., \& McCauley, C. R. (2000). Disgust. In M. Lewis \& J. M. Haviland-Jones (Eds.) Handbook of emotions (pp. 637-653). New York: Guilford Press.

Salkovskis, P. M., Rimes, K. A., Warwick, H. M. C., \& Clark, D. M. (2002). The health anxiety inventory: Development and validation of scales for the measurement of health anxiety and hypochondriasis. Psychological Medicine, 32, 843-853.

Salkovskis, P. M., Warwick, H. M. C., \& Clark, D. M. (1990).

Spielberger, C. D., Gorsuch, R. L., Lushene, R. E., Vagg, P. R., \& Jacobs, G. A. (1983). Manual for the State-Trait Anxiety Inventory. Palo Alto, CA: Consulting Psychologists Press.

Steketee, G., Chambless, D. L., Tran, G. Q., Worden, H., \& Gillis, M. M. (1996). Behavioral avoidance test for obsessive-compulsive disorder. Behaviour Research and Therapy, 34, 73-83.

Tabachnick, B. G., \& Fidell, L. S. (2007). Using multivariate statistics. (5 ${ }^{\text {th }}$ ed). Boston, MA: Allyn \& Bacon.

Thorpe, S. J., Patel, S. P., \& Simonds, L. M. (2003). The relationship between disgust sensitivity, anxiety, and obsessions. Behaviour Research and Therapy, 41, 1397-1409.

Tolin, D. F., Woods, C. M., \& Abramowitz, J. S. (2006). Disgust sensitivity and obsessivecompulsive symptoms in a non-clinical sample. Journal of Behavior Therapy and Experimental Psychiatry, 37, 30-40.

Tsao, S. D., \& McKay, D. (2004). Behavioral avoidance tests and disgust in contamination fears: distinctions from trait anxiety. Behaviour Research and Therapy, 42, 207-216. 
Tybur, J. M., Lieberman, D., \& Griskevicius, V. (2009). Microbes, mating, and morality: Individual differences in three functional domains of disgust. Journal of Personality and Social Psychology, 97, 103-122.

van Overveld, W. J. M., de Jong, P. J., Peters, M. L., Cavanagh, K., \& Davey, G. C. L. (2006). Disgust propensity and disgust sensitivity: separate constructs that are differentially related to specific fears. Personality and Individual Differences, 41, 12411252.

Warwick, H. M. C., \& Salkovskis, P. M. (1990). Hypochondriasis. Behaviour Research and Therapy, 28, 105-117. doi:10.1016/0005-7967(90)90023-C.

Zinbarg, R. E., Suzuki, S., Uliaszek, A. A., \& Lewis, A. R. (2010). Biased parameter estimates and inflated type I error rates in analysis of covariance (and analysis of partial variance) arising from unreliability: Alternatives and remedial strategies. Journal of Abnormal Psychology, 119, 307-319. 


\section{TABLES AND FIGURES}

Table 1.

Means for BAT variables, SHAI, PI-COWC, PVD, DPSS-R, STAI-T, and EPQ-NR by Group

\begin{tabular}{|c|c|c|c|c|c|c|}
\hline \multirow[b]{2}{*}{ Measure } & \multicolumn{2}{|c|}{ Health Anxious } & \multicolumn{2}{|c|}{ Contamination Fear } & \multicolumn{2}{|c|}{ Non-anxious Control } \\
\hline & M & SD & M & SD & $\mathrm{M}$ & SD \\
\hline BAT Avoidance & 6.3 & 2.79 & 7.21 & 1.65 & 3.4 & 2.58 \\
\hline BAT Anxiety & 2.67 & 1.79 & 3.20 & 1.52 & 0.55 & 0.8 \\
\hline BAT Disgust & 3.38 & 1.77 & 4.05 & 1.66 & 0.95 & 0.92 \\
\hline SHAI & 26.45 & 10.14 & 13.00 & 5.84 & 5.75 & 4.02 \\
\hline PI-COWC & 13.20 & 7.82 & 23.26 & 7.47 & 3.30 & 3.80 \\
\hline PVD & 64.95 & 19.26 & 66.68 & 9.98 & 39.1 & 15.62 \\
\hline DPSS-R & 44.40 & 13.94 & 46.37 & 8.32 & 28.15 & 7.87 \\
\hline STAI-T & 51.90 & 11.27 & 40.26 & 8.31 & 32.05 & 7.76 \\
\hline EPQ-NR & 8.5 & 2.37 & 6.26 & 2.83 & 2.15 & 1.93 \\
\hline
\end{tabular}


Table 2.

Summary of zero-order intercorrelations for BAT variables, SHAI, PI-COWC, PVD, and DPSS-R.

\begin{tabular}{|c|c|c|c|c|c|c|c|}
\hline Measure & 1 & 2 & 3 & 4 & 5 & 6 & 7 \\
\hline 1. BAT Avoidance & -- & & & & & & \\
\hline 2. BAT Anxiety & $.39 * *$ & -- & & & & & \\
\hline 3. BAT Disgust & $.44 * *$ & $.88 * *$ & -- & & & & \\
\hline 4. SHAI & $.33^{*}$ & $.53 * *$ & $.50 * *$ & -- & & & \\
\hline 5. PI-COWC & $.59 * *$ & $.59 * *$ & $.67 * *$ & $.40 * *$ & -- & & \\
\hline 6. PVD & $.57 * *$ & $.51 * *$ & $.56 * *$ & $.53 * *$ & $.73 * *$ & -- & \\
\hline 7. DPSS-R & $.44 * *$ & $.57 * *$ & $.62 * *$ & $.62 * *$ & $.76^{* *}$ & $.77 * *$ & -- \\
\hline
\end{tabular}




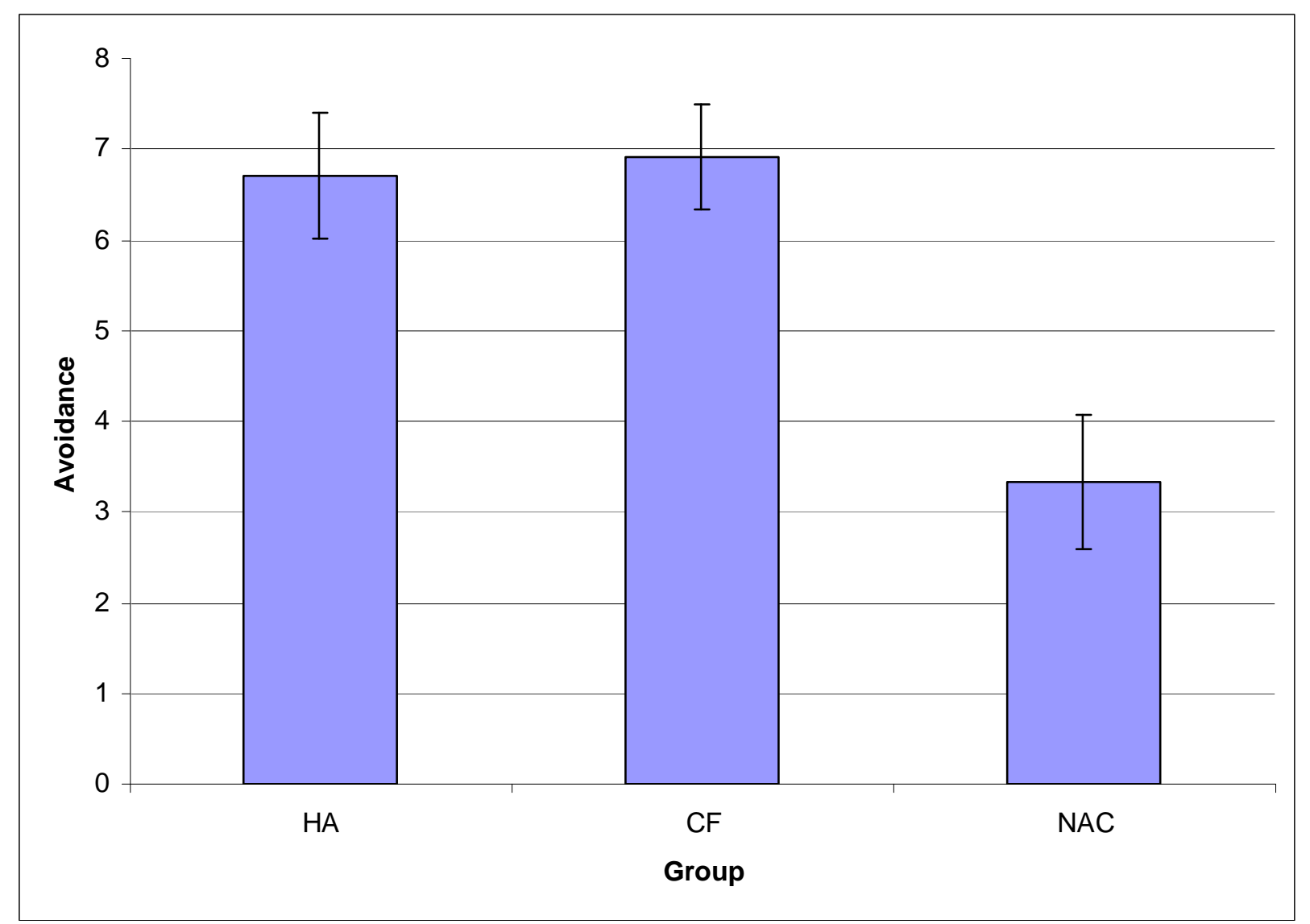

Figure 1. Estimated marginal mean avoidance scores on the BATs as a function of group. There were significant differences between the pathological groups and the non-anxious controls, but not between the health anxious and contamination fearful groups. Standard errors are represented by the error bars attached to each column. $\mathrm{HA}=$ Health Anxious; $\mathrm{CF}=$ Contamination Fearful; NAC $=$ Non-anxious Controls. 


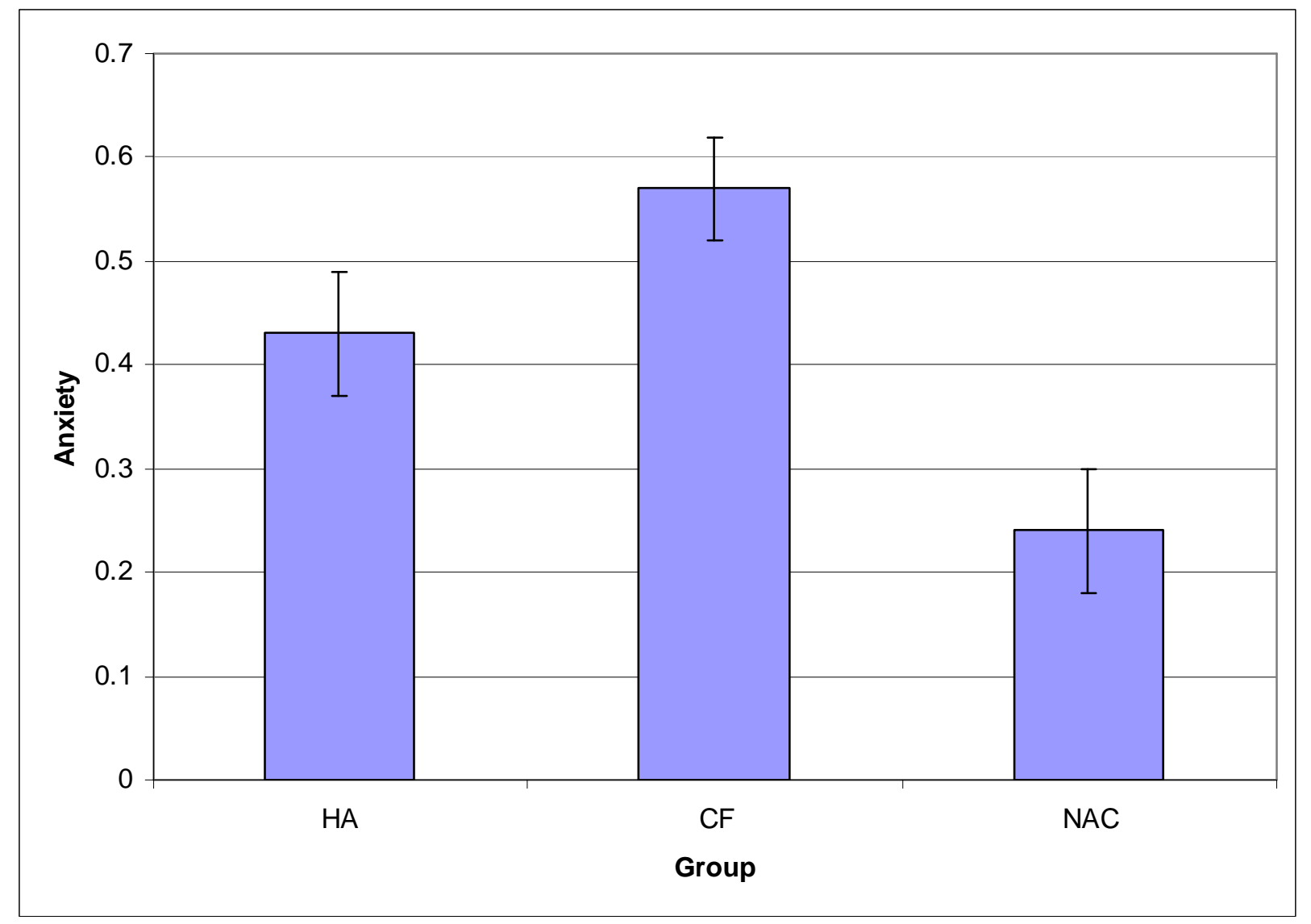

Figure 2. Estimated marginal mean log-transformed anxiety ratings as a function of group. There was a significant difference between the CF and NAC groups, but not between the CF and HA groups. The HA group was not significantly different from the NAC group Standard errors are represented by the error bars attached to each column. $\mathrm{HA}=$ Health Anxious; $\mathrm{CF}=$ Contamination Fearful; NAC $=$ Non-anxious Controls. 


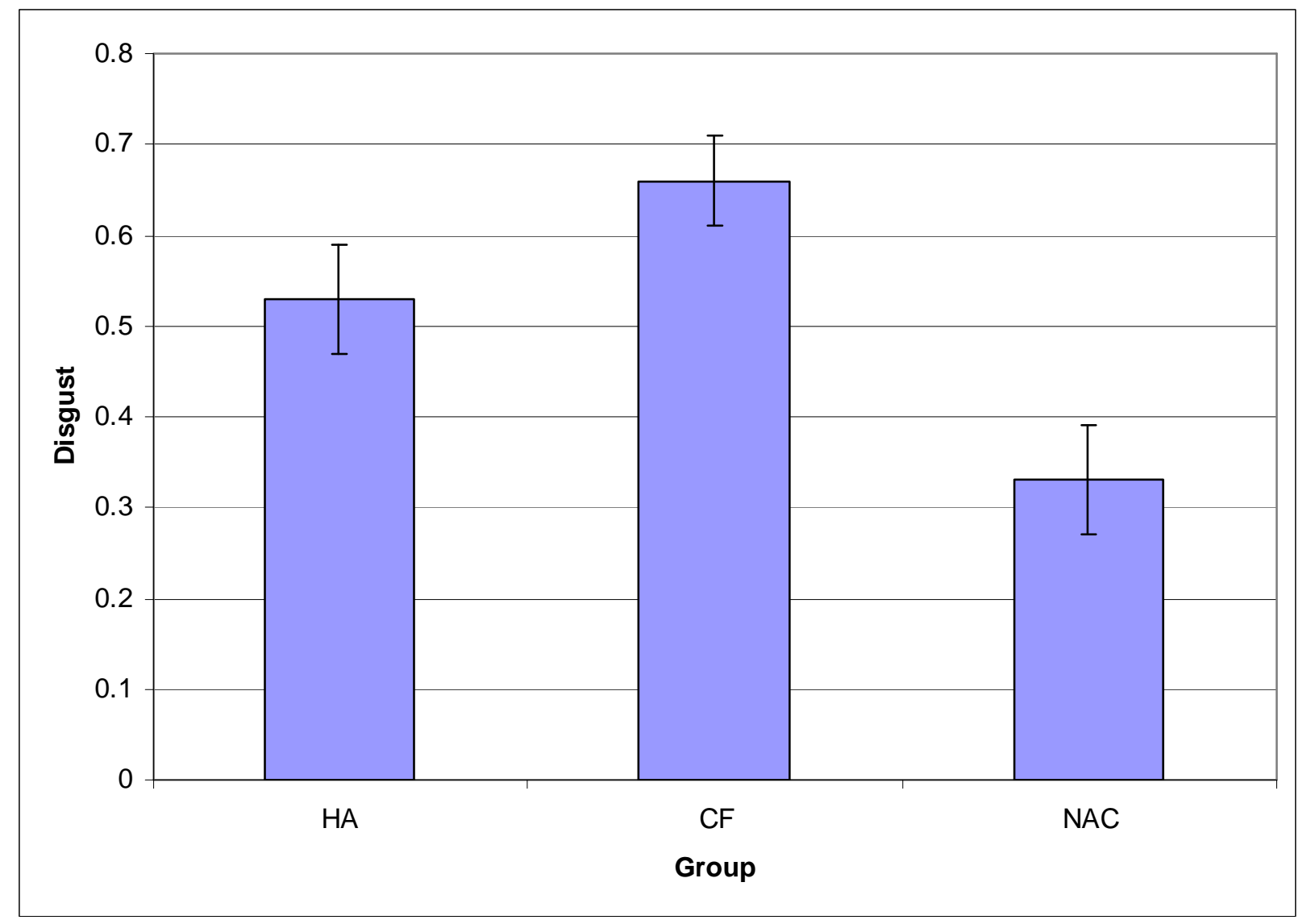

Figure 3. Estimated marginal mean log-transformed disgust ratings as a function of group. There was a significant difference between the CF and NAC groups, but not between the CF and HA groups. The HA group was not significantly different from the NAC group Standard errors are represented by the error bars attached to each column. $\mathrm{HA}=$ Health Anxious; $\mathrm{CF}=$ Contamination Fearful; NAC $=$ Non-anxious Controls. 


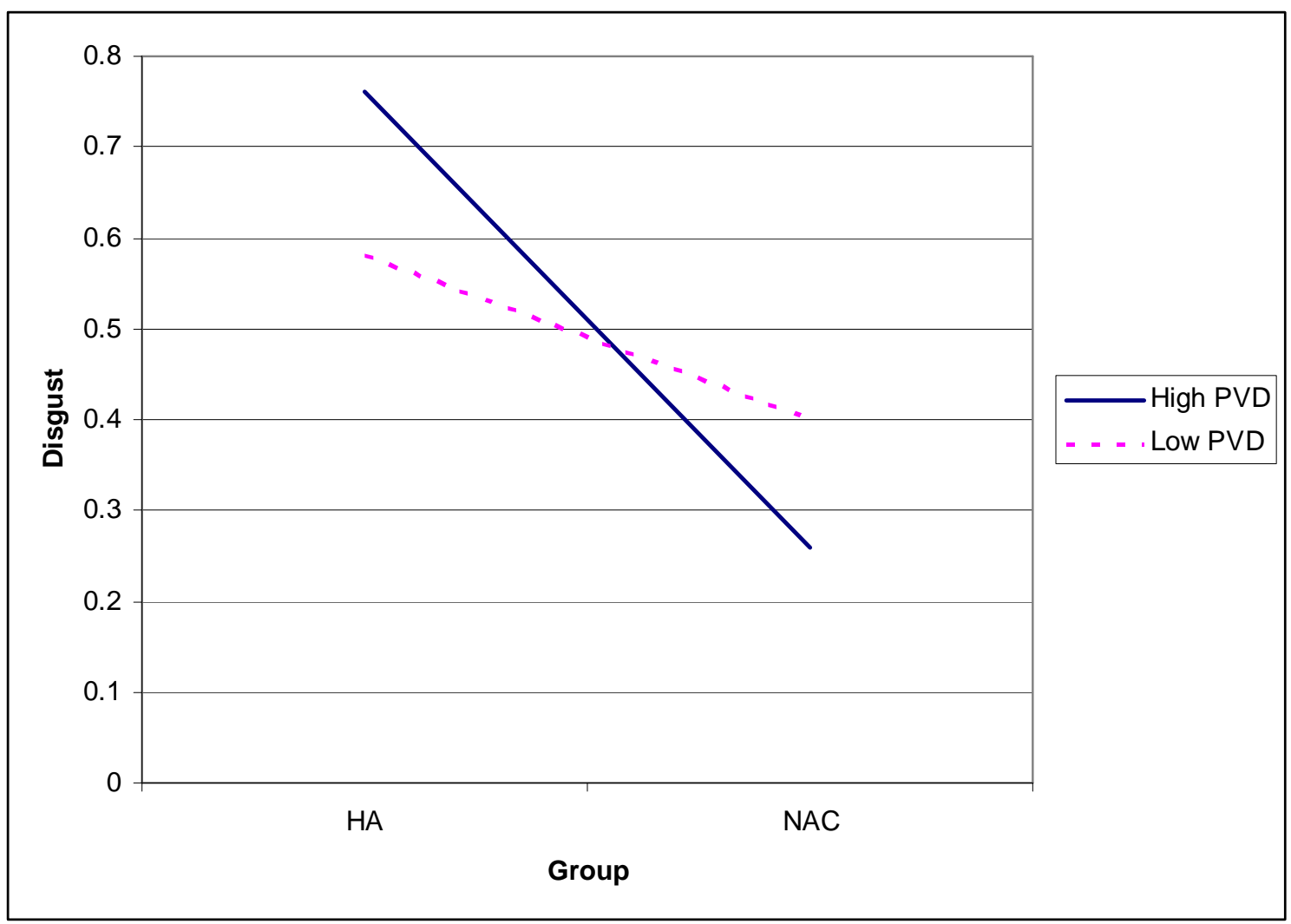

Figure 4. Interaction of HA and PVD in the prediction of disgust. Group membership was a significant predictor of disgust ratings on the BATs when PVD was high (solid line), but not when PVD was low (dotted line). HA = Health Anxious; NAC = Non-anxious Controls; PVD = Perceived vulnerability to disease. 


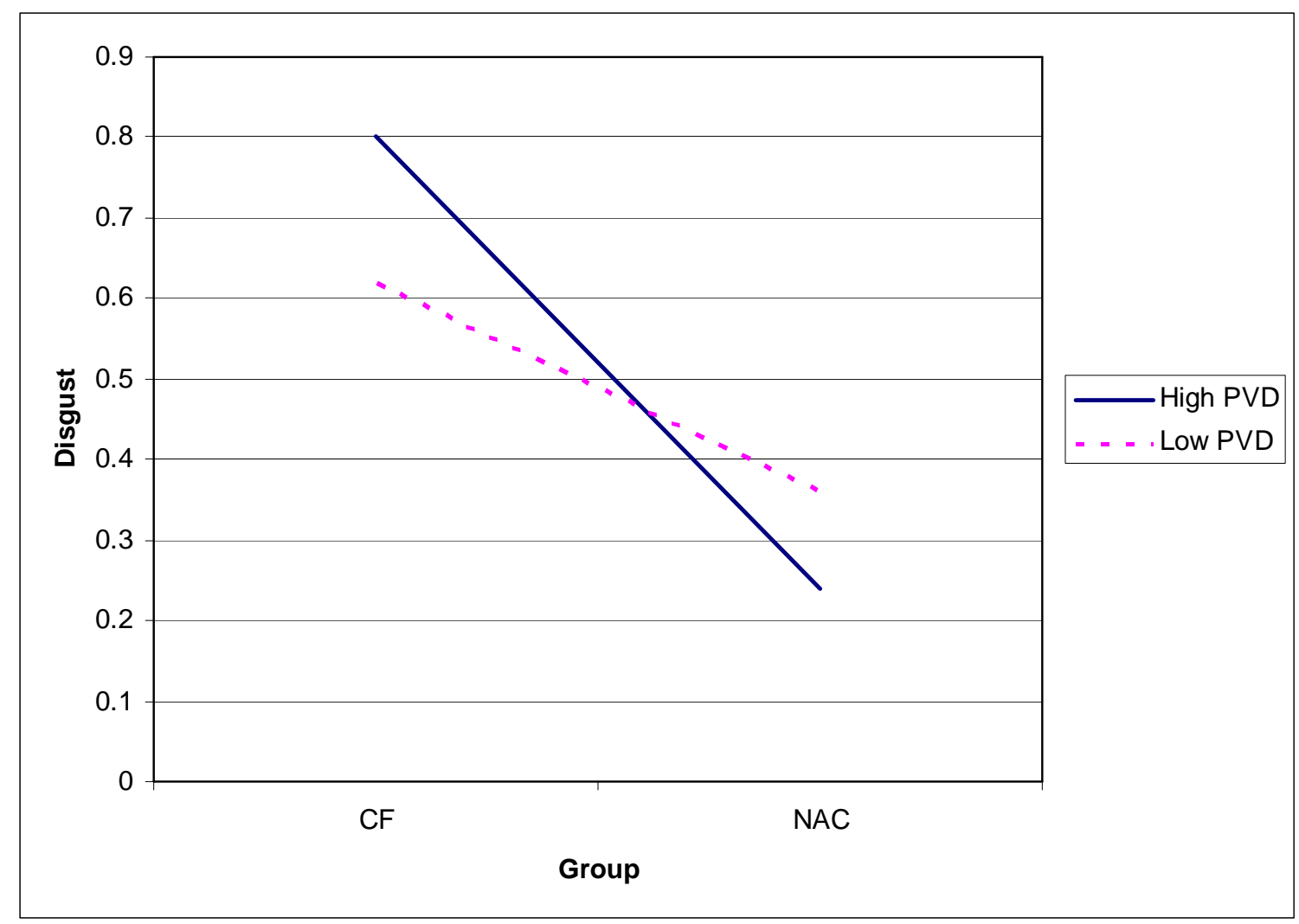

Figure 5. Interaction of CF and PVD in the prediction of disgust. Group membership was a significant predictor of disgust ratings on the BATs when PVD was high (solid line), but not when PVD was low (dotted line). CF = Contamination Fearful; NAC = Non-anxious Controls; $\mathrm{PVD}=$ Perceived vulnerability to disease. 


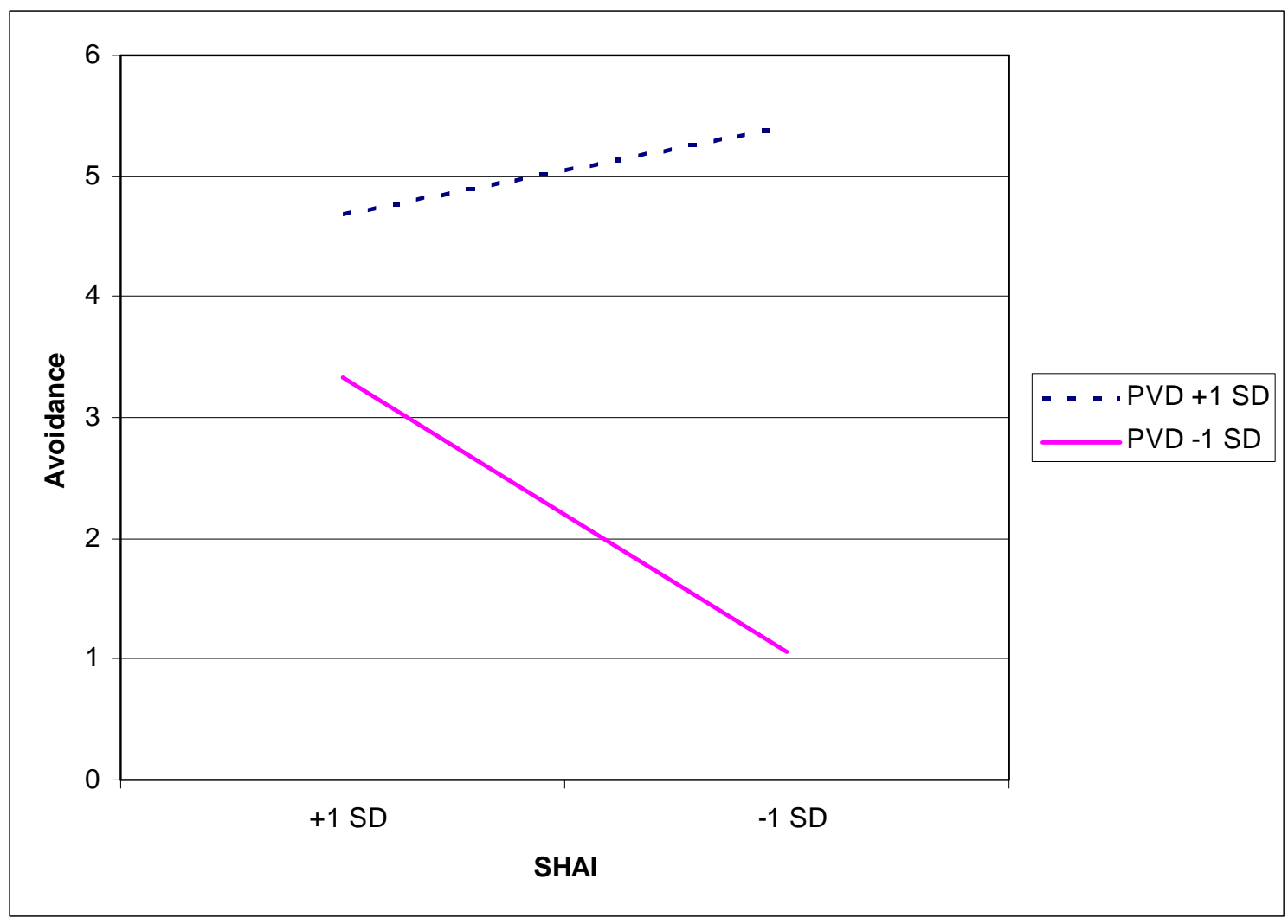

Figure 6. Interaction of SHAI and PVD in the prediction of avoidance. SHAI was a significant predictor of avoidance on the BATs when PVD was low (solid line), but not when PVD was high (dotted line). SHAI $=$ Short Health Anxiety Inventory; PVD $=$ Perceived Vulnerability to Disease. 
